\title{
An Investigation on the Effect of Heat Treatment on the Compression Behavior of Aluminum Matrix Syntactic Foam Fabricated by Sandwich Infiltration Casting
}

\author{
Çăğın Bolat ${ }^{a *}$ (D), Gökhan Bilge ${ }^{b}$ (D), Ali Gökşenlia ${ }^{(1)}$ \\ ${ }^{a}$ Istanbul Technical University, Faculty of Mechanical Engineering, Istanbul, Turkey \\ ${ }^{b}$ Turkish Aerospace Industry, Ankara, Turkey
}

Received: August 22, 2020; Revised: November 21, 2020; Accepted: January 10, 2021

\begin{abstract}
In this research, syntactic foams including Al-7075 matrix and 2-4 mm low-cost pumice particles were manufactured via a novel casting method called as sandwich infiltration. According to physical evaluations, thanks to extremely porous structure of pumice, density values of the fabricated foams varied between 1.42 and $1.61 \mathrm{~g} / \mathrm{cm}^{3}$. Porosity values were between $40.62 \%$ and $47.39 \%$. Microstructural observations showed that there was a perfect infiltration between $\mathrm{Al}$ matrix and pumice particles because of correct process optimization (process pressure of $0.1 \mathrm{MPa}$, matrix melting temperature of $720^{\circ} \mathrm{C}$ and filler pre-temperature of $500^{\circ} \mathrm{C}$ ). Furthermore, T6 treatment was applied to samples to comprehend effect of the aging on mechanical properties. The results indicated that there was an affirmative relation between the heat treatment and quasi-static compressive properties of the fabricated foams. The highest compressive strength, plateau stress and energy absorption values were measured as $64.4 \mathrm{MPa}, 74.3 \mathrm{MPa}$ and $34 \mathrm{MJ} / \mathrm{m}^{3}$ for heat treated samples. It was also observed that although the highest energy efficiency of 0.89 was calculated for heat treated sample, there was no relation between the heat treatment and efficiency. As for failure modes, as-cast samples exhibited ductile barreling characteristic whereas T6 treated foams indicated brittle v-shape fracture.
\end{abstract}

Keywords: syntactic metal foam, sandwich casting, heat treatment, compressive behavior, deformation mechanism.

\section{Introduction}

Metal matrix syntactic foams (MMSFs) have come into the forefront in recent times because of their superior compressive properties, low densities, good strength to weight ratios and perfect energy absorption abilities ${ }^{1,2}$. These advanced materials have been thoroughly investigated by certain researchers to explore their mechanical, structural and thermal features. Even though the lowest producible density levels are usually higher than standard open or close cell metallic foams, MMSFs have superior mechanical properties compared to traditional metal foams ${ }^{3}$. Typically, the MMSFs consist of two main components: metallic matrix material and filler component. In the technical literature, while aluminum, magnesium, steel, titanium and zinc alloys are often preferred as matrix materials ${ }^{4-7}$, thin walled hollow ceramics and porous fly ash cenospheres are used as fillers ${ }^{8-10}$. Also, recently, since spherical hollow ceramic and glass fillers have high cost and require complex manufacturing methods, researchers have inclined to cheap alternatives like expanded perlite (EP) which is an extremely light volcanic glass and fly ash cenospheres which are the product of coal burning ${ }^{11,12}$.

Thanks to porous/cellular or thin walled hollow filler additives, MMSFs exhibit excellent compressive properties together with good energy absorption under mechanical loading and this situation strongly depends on harmony of the matrix-filler combination ${ }^{1,2,10}$. In addition to many advantageous mechanical properties of the MMSFs, their promising feasibility

*e-mail: caginbolat@itu.edu.tr for casting process and great potential for being alternative to conventional particle reinforced composites and classical metal foams are very significant on the road to probable real industrial applications. In this point, automotive, railway, aerospace and construction industries can be considered as major target sectors for the real MMSF applications by reason of the fact that ductility, energy absorption and lightness are highly critical for many design components ${ }^{10,13}$. Moreover, especially for automotive and aerospace sectors, it should also be emphasized to say that along with decreasing total design weight without a noteworthy strength drop in structural parts, fuel efficiency automatically goes up and environmental pollution can be diminished.

Traditional metal foams are manufactured with a lot of different techniques from chemical ways to powder metallurgical approaches ${ }^{14}$. Similarly, MMSFs can be manufactured with various technical methods such as mechanical melt stirring, gravity assisted infiltration, counter gravity infiltration, pressureless infiltration, gas/vacuum pressure infiltration and powder metallurgical ways ${ }^{15-20}$. Each method has its own advantages and drawbacks depending on the application and usage conditions. For example, by powder metallurgical method, although it is a promising method, the fracture risk of filler spheres of still exists owing to process pressure and direct contact between matrix and filler granules. Stir casting method, in which hollow spheres are poured inside liquid metal and blended, has the advantage of low cost and easily application, but the disadvantages are that filler sphere damage 
may occur during the mechanical mixing process and an inhomogeneous structure due to density variation may form. Also, control of the filler distribution in the metal matrix is difficult task in this technique. On the other hand, gas/vacuum assisted techniques can provide uniform filler distribution but they require some additional expensive apparatus. Therefore, it is clear that fabrication of the MMSFs can't be designated without taking the certain critical factors like fabrication cost, duration, dimensional accuracy, product inner quality, repeatability and adaptability into consideration. In this investigation, as fabrication method, sandwich infiltration casting method, which was developed by our team, was used. This novel method is a mixture of gravity assisted and counter gravity melt infiltration techniques to form a homogeneous matrix/ filler structure along with the accurate part geometry.

Lately, efforts about aluminum matrix syntactic foams (AMSFs) have increased on a large scale majorly from the point of mechanical properties. Many different aluminum alloy series are utilized with several filler types in order to examine mechanical features and to comprehend deformation mechanisms exhaustively. For instance, Orbulov et al. ${ }^{21}$, by applying three-point bending test, investigated notch sensitivity of Al matrix syntactic foams manufactured via pressure infiltration casting. The researchers revealed that due to different chemical bonding between matrix and fillers crack propagation of A199.5 was different from AlSi12. In another effort, Taherishargh et al. ${ }^{22}$ studied high temperature compressive behavior of expanded perlite/A356 syntactic foam and reported that increasing temperature led to smoother stress-strain curves and better ductility. Goel et al. ${ }^{23}$ tried to explain high strain rate compression response of fly ash cenosphere/A12014 foam by conducting split Hopkinson pressure bar test. As a consequence of their work, the authors alleged that high loading rates resulted in higher strength levels. Akinwekomi et $\mathrm{al}^{0}$ fabricated $\mathrm{Al} / \mathrm{fly}$ ash cenosphere foams by using powder metallurgy and hybrid microwave sintering and it minimized negative effect of interfacial brittleness. Hao et al. ${ }^{24}$ indicated that mechanical properties of cp-Al/alumina and ZL111/alumina foams enhanced with decreasing sphere size. Fiedler et al. ${ }^{25}$ reported that thermal treatment improved mechanical response of A356 syntactic foam at cryogenic temperature $\left(-196^{\circ} \mathrm{C}\right)$. Orbulov et al. ${ }^{26}$ recommended expanded clay particles for commercial purity $\mathrm{Al}$ and AlSi9MgMn matrices to try low-cost and useful alternative to the widely used hollow spheres, and emphasized that T6 treatment enhanced mechanical properties. Fiedler et al. ${ }^{27}$ fabricated functionally graded A356/EP syntactic foam. The research group concluded that particle pre-compaction was effective for density diminishment and it converted the fracture characteristic from barreling to layer by layer deformation. In another interesting study, Hao et al..$^{28}$ investigated mechanical properties of hybrid expanded glass/ hollow alumina sphere filled ZL111 matrix syntactic foam. The research team expressed that as the expanded glass content increased, compressive strength and plateau stress of the fabricated foam dwindled, but fracture strain value went up. Thalmaier et al. ${ }^{29}$ tried a new manufacturing method and showed that syntactic foams could be produced from aluminum sawing chips. Sahu et al. ${ }^{30}$ used stir-casting method for manufacturing of $25 \mathrm{vol} . \%$ cenosphere filled Al 2014 syntactic foam. The research team found that even though foam density was $2 \mathrm{~g} / \mathrm{cm}^{3}$, the compressive strength was high and limited strain hardening effect was seen in the plateau region. Broxtermann et al. ${ }^{31}$ compared stir-casting and infiltration casting methods for aluminum syntactic fabrication. As a result of their work, the researchers reported that although infiltrated foams displayed vertical density gradient, this case was not valid for stir casted foams.

In order to analyze the probable effect of heat treatment on the mechanical properties of MMSFs, some researchers studied Al and $\mathrm{Zn}$ alloys as matrix materials due to their largescale usage in several industrial applications. In this context, Taherishargh et al. ${ }^{32}$ carried out artificial aging treatment (T6) on expanded perlite reinforced aluminum A356 syntactic foams and stated that the T6 treatment improved plateau strength and absorbed energy of the produced samples. In another work, Movahedi et al. ${ }^{33}$ focused on effects of the heat treatment operation on the compressive features of expanded perlite filled Zinc(ZA27) syntactic foam and reported that specific energy absorption, plateau stress, and energy absorption efficiency of produced foams improved following the heat treatment. Similar enhancements in the compressive properties were also observed for $\mathrm{T} 6$ treated ceramic microspheres ( $45 \mathrm{vol} . \%$ $3 \mathrm{Al}_{2} \mathrm{O}_{3}-2 \mathrm{SiO}_{2}$ and 55 vol. $\% \mathrm{SiO}_{2}$ ) reinforced $\mathrm{Al} 7075$ syntactic foam by Dunand et al. ${ }^{34}$. Santa Maria et al. ${ }^{35}$ studied on effects of T4 and T7 heat treatments on the deformation behaviors of $\mathrm{Al} 206 / \mathrm{Al}_{2} \mathrm{O}_{3}$ syntactic foam and the researchers pointed that heat treated foams had higher average peak strength and specific plateau strength values than their as-cast versions.

In this research, contrary to widely used Al-Si cast alloys, Al 7075 alloy was used as matrix material due to its widespread usage in several industrial applications and T6 heat treatment availability. As for filler material, pumice, which is a naturally occurred extremely porous volcanic rock, was picked out owing to its unique cellular structure and cost effectiveness in comparison with expensive engineered hollow ceramic spheres. Pumice have rarely been investigated as a filler material syntactic foams in previous studies ${ }^{36}$. Unfortunately, no investigations were carried out on the effect of heat treatment on pumice reinforced syntactic foams. The main targets of the present work are to obtain perfect matrix/filler harmony by means of new developed sandwich infiltration casting method and to analyze the effect of T6 heat treatment on pumice reinforced Al 7075 syntactic foams.

\section{Materials and Method}

\subsection{Materials}

A wide range of $\mathrm{Al}$ alloys have been used in lots of applications for a long time and they basically are divided into two groups namely heat treatable and work hardened alloys ${ }^{37}$. 7000 series of Al alloys, mostly with heat treated state, are preferred by aeronautics and space industries for aircraft fittings, gears, and shafts. Besides, that series of $\mathrm{Al}$ alloys are also used in other sectors like automotive (car body parts), defense/military services (missile parts) and outdoor applications (climbing equipment, bicycle components). In this paper, as matrix alloy, Al 7075 was used and supplied from Güray Aluminum Limited Company (Istanbul, Turkey). This alloy composes of $5.68 \mathrm{wt} \%$ zinc, $2.39 \mathrm{wt} \%$ magnesium, $1.4 \mathrm{wt} \%$ copper, $0.21 \mathrm{wt} \%$ iron, $0.2 \mathrm{wt} \%$ silicon, $0.18 \mathrm{wt} \%$ 
manganese, $0.034 \mathrm{wt} \%$ titanium and $0.018 \mathrm{wt} \%$ zirconium. For reinforcement material, 2-4 $\mathrm{mm}$ pumice particles (65 wt $\% \mathrm{SiO}_{2}, 11.7$ wt $\% \mathrm{Al}_{2} \mathrm{O}_{3}, 4.12 \mathrm{wt} \% \mathrm{Na}_{2} \mathrm{O}, 4.1 \mathrm{wt} \%$ $\mathrm{K}_{2} \mathrm{O}, 1.75 \mathrm{wt} \% \mathrm{Fe}_{2} \mathrm{O}_{3}, 0.55 \mathrm{wt} \% \mathrm{CaO}, 0.03 \mathrm{wt} \% \mathrm{TiO}_{2}$ and trace quantity of others) were received from Miner Mining and Transportation Limited Company (Nevsehir, Turkey), were soaked in water and low density floating particles were parsed out from damaged particles and impurities like stone and sand fragments. According to the supplier information, certain physical features of the pumice can be found in Table 1 .

\subsection{Fabrication method}

In the AMSFs fabrication, a new manufacturing method called "sandwich infiltration casting" was used. If the method briefly explained, at the beginning, the steel mold shown in Figure 1 and a graphite crucible in which $\mathrm{Al}$ alloy was settled were put into the electrical resistance furnace $\left(1100^{\circ} \mathrm{C}\right.$ max. capacity) and were heated up to $720^{\circ} \mathrm{C}$. All of these equipment was kept in the furnace for $25 \mathrm{~min}$. The volume of the molten alloy was higher than the volume of the filler with intend to make complete infiltration and to form flawless foam structure. In the sandwich casting, except for the preheating procedure, all process steps were performed outside of the furnace. Firstly, the steel mold was taken out of the furnace and $50 \mathrm{wt} \%$ of fillers were poured into the mold cavity. Then,

Table 1. Physical properties of the pumice particles.

\begin{tabular}{lc}
\hline \multicolumn{1}{c}{ Property } & Result \\
\hline Bulk density $\left(\mathrm{g} / \mathrm{cm}^{3}\right)$ & $0.50-0.60$ \\
\hline Specific heat capacity $(\mathrm{J} /(\mathrm{kg} . \mathrm{K}))$ & $1.00-1.08$ \\
\hline Thermal conductivity $(\mathrm{W} /(\mathrm{m} . \mathrm{K}))$ & $0.11-0.21$ \\
\hline Softening temperature $\left({ }^{\circ} \mathrm{C}\right)$ & 1240 \\
\hline
\end{tabular}

the molten and dross removed liquid $\mathrm{Al}$ was added on with the help of the graphite crucible. Before addition into the mold, all pumice particles were preheated to $5_{00}^{\circ} \mathrm{C}$ so as to remove moisture and to block early solidification of molten $\mathrm{Al}$ during the infiltration. Immediately after the initial filtration through gravitational way, remain particles were put on the semi-finished mixture to fulfill full infiltration by the way of counter gravity effect. In the final infiltration step, mechanical pressure of $0.1 \mathrm{MPa}$ was applied with lubricated (Trewa S grease oil) steel plunger.

After the casting operation, medium fit steel plunger, which provides evacuation of excess alloy and enough ventilation, was taken apart. The mold parts and fabricated foam sample were cooled down at room temperature in air. Finally, the mold was carefully opened and the syntactic sample was ejected manually. As a result of the sandwich infiltration, we manufactured cylindrical syntactic samples having $25 \pm 0.3 \mathrm{~mm}$ diameter and $33 \pm 0.6 \mathrm{~mm}$ length. With the average value of 1.49 $\mathrm{g} / \mathrm{cm}^{3}$, density values of the produced foams varied between 1.42 and $1.61 \mathrm{~g} / \mathrm{cm}^{3}$. Half of the specimens having similar or same density values with the others were singled out for T6 heat treatment comprising of solution treatment at $480^{\circ} \mathrm{C}$ for $2 \mathrm{~h}$ and aging at $120^{\circ} \mathrm{C}$ for $24 \mathrm{~h}$. Basically, T6 treatment of 7000 series of Al alloys, comprises of supersaturated solution treatment, Guiner Preston (GP) zones and aging treatment for precipitations, and secondary precipitates (especially $\mathrm{MgZn}_{2}$ ) are decisive on final hardness of the alloy ${ }^{38}$.

Detailed manufacturing scheme can be found in Figure 2. Thanks to the sandwich infiltration technique designed by our research team, some remarkable advantages can be attained. For instance, due to free pumice particles, crack propagation may be blocked by metallic matrix under different loading conditions. However, this case is quite opposite to other techniques using physical contacted preforms leading to fast
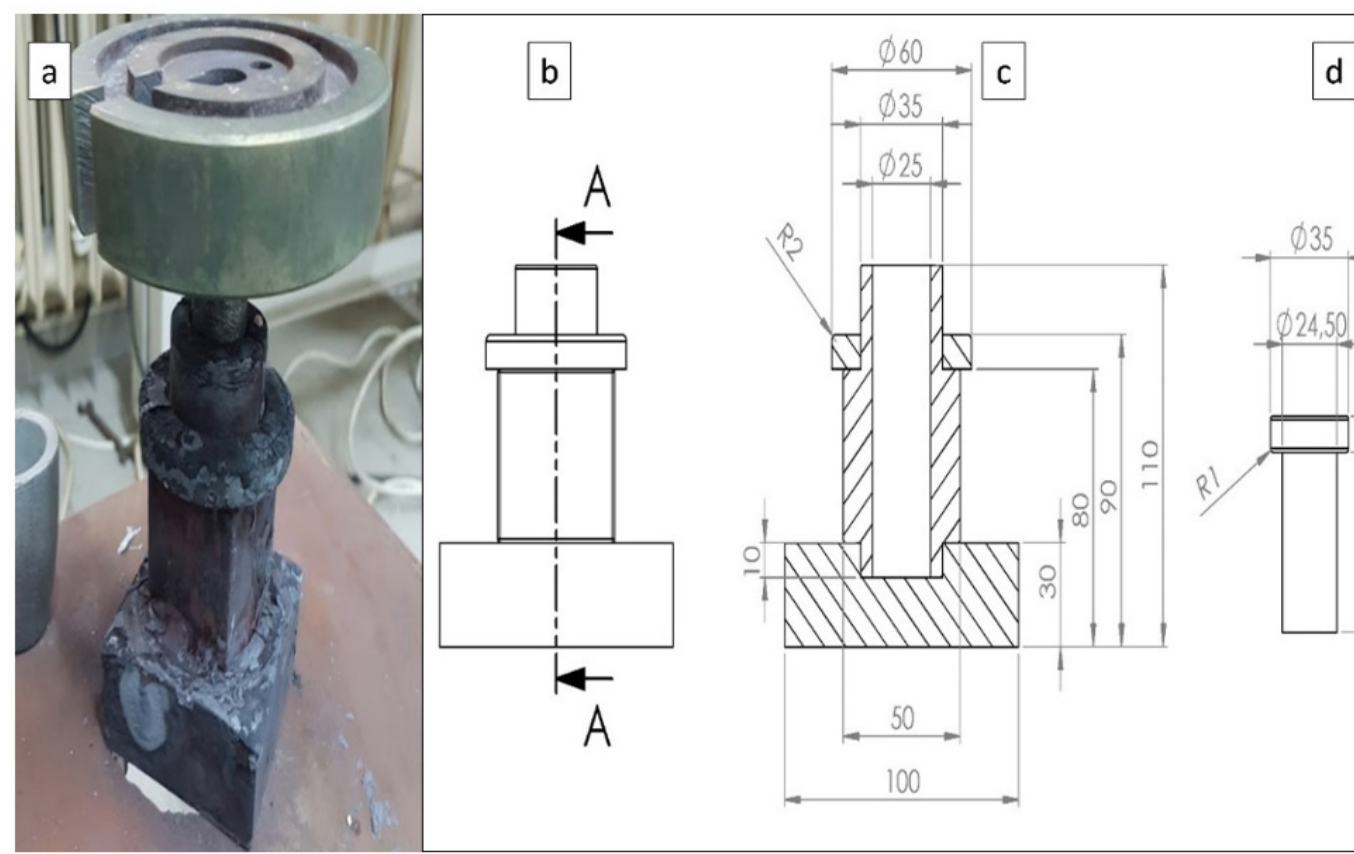

Figure 1. The mold used in AMSF production (a) and its technical drawings; front view(b), cross-sectional view(c) and front view of steel plunger(d). 


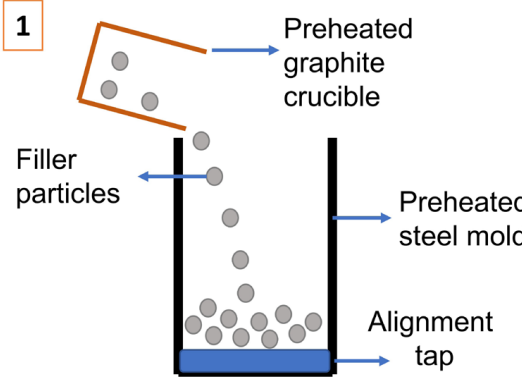

3

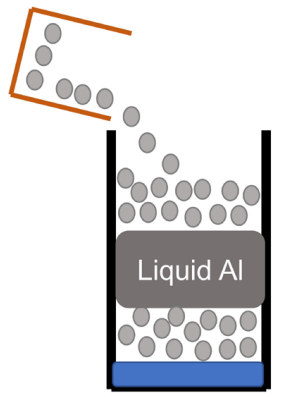

2
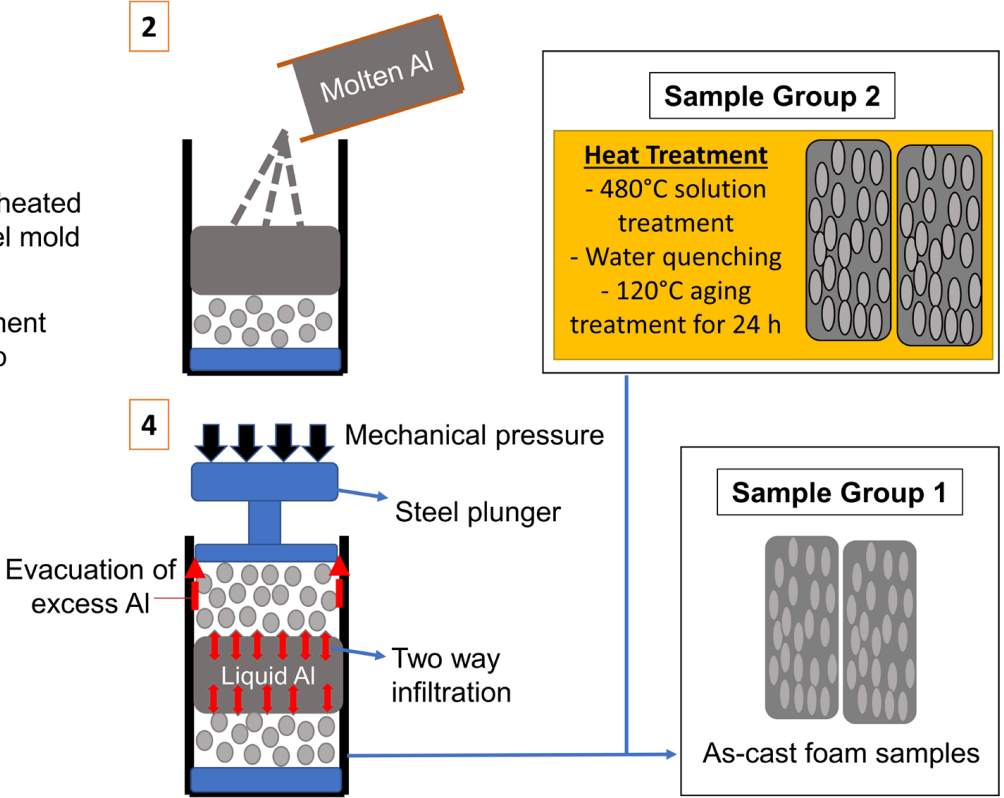

Sample Group 1

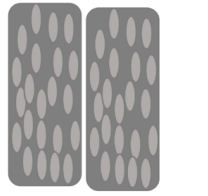

As-cast foam samples

Figure 2. Schematic view of the sandwich infiltration casting.

crack propagation from particle to particle. What's more, the sandwich infiltration can be defined as a simple method consisting of only a steel mold and a cylindrical steel plunger in comparison with other methods requiring specially designed ceramic filtration molds, alloyed steel meshes or extra gas/ vacuum equipment. At the end of the process, any secondary operations as turning, milling or full surface cutting is not necessary and only some minor cleaning process like grinding and deburring are enough for further analysis. Furthermore, infiltration stage of the sandwich casting method is carried out outside of the furnace at the room temperature, so the amount of solved gases and probability of filler/matrix reaction can be diminished because of rapid solidification.

\subsection{Sample characterization}

In the stage of physical characterization, foam density $\left(\varphi_{\text {syn }}\right)$, volume fraction of filler particles $\left(\mathrm{F}_{\mathrm{Fil}}\right)$ and total porosity percentage $\left(\mathrm{F}_{\mathrm{TP}}\right)$ were calculated. Density of the foam samples were calculated by using the Equation 1 written below;

$\varphi_{s y n}=\frac{m_{s y n}}{V_{s y n}}$

$\mathrm{V}_{\text {syn }}$ and $\mathrm{m}_{\text {syn }}$ are the volume and mass of the samples. For determination of volume fraction of filler particles and total porosity percentage, equations reported by Taherishargh et al. ${ }^{11}$ was used. Besides, in Equation 2, Equation 3 and Equation 4, $\mathrm{m}_{\text {fil }}, \rho_{\text {fil }}, \rho_{\text {alu }}$ and $\rho_{\text {sd }}$ are the mass of pumice, particle density of pumice, density of the matrix and density of solid state of the pumice respectively.

$$
\begin{aligned}
& F_{\text {fil }}=\left[\left(V_{\text {syn }}-\left(m_{\text {syn }}-m_{\text {fil }}\right) / \rho_{\text {alu }}\right) / V_{\text {syn }}\right] 100 \\
& \rho_{\text {fil }}=m_{\text {fil }} /\left[V_{\text {syn }}-\left(m_{\text {syn }}-m_{\text {fil }}\right) / \rho_{\text {alu }}\right]
\end{aligned}
$$

$F_{T P}=F_{f i l}\left[1-\left(\rho_{f i l} / \rho_{s d}\right)\right]$

Both macroscopic and microscopic observations were carried out elaborately in order to analyze structural features of the fabricated syntactic foams. Samples were cut neatly with band-saw and grinded with Metcon Forcipol 2V (Bursa, Turkey) machine. SiC abrasive papers were used from coarse grit (180) to fine grit (1200) before polishing process which was implemented by utilizing $1 \mu$ Metkon Diapat diamond suspension. Polished samples were placed in an ultrasonic bath for final cleaning since they might have some contaminants or unwanted accumulations. Fei Quante Feg 250 (Oregon, USA) model scanning electron microscope (SEM), Nikon Eclipse LV150L (Tokyo, Japan) and Nikon SMZ800 (Tokyo, Japan) model optical microscopes with DpxView-Pro software were made use of on the purpose of detailed micro observations.

Compression tests were performed on samples at the room temperature and computer controlled $50 \mathrm{KN}$ Shimadzu AG-IS (Kyoto, Japan) uniaxial testing machine cooperating with Trapezium 2 data acquisition software was used. During all tests, the load and displacement of the press head were recorded and turned into engineering stress-strain curves by utilizing initial foam sample height and cross sectional area. Compression platens moving with $1 \mathrm{~mm} / \mathrm{min}$ deformation rate (quasi-static condition) was applied for both untreated and heat treated samples. Before each test, in order to apply uniform uniaxial loading and to hinder barreling, a lubricant was rubbed on top and bottom surfaces of compression platens. Additionally, by using a digital camera, we recorded all tests to understand failure mechanism of the foams better.

Some major properties such as compression stress, plateau stress, densification strain, fracture strain and energy absorption were determined in accordance with ISO 13314 standard $^{39}$. In the elastic region, slope of the linear section 


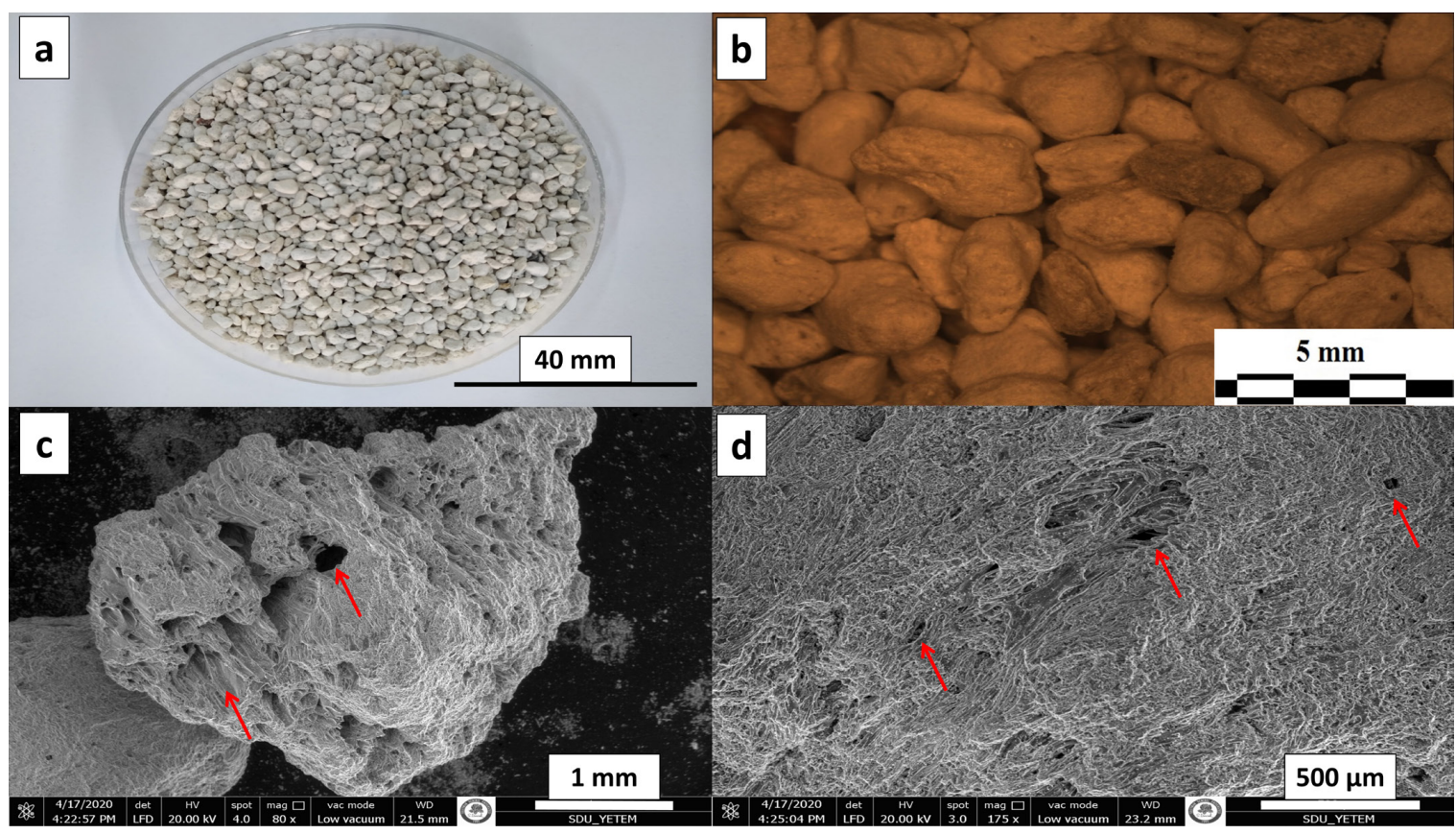

Figure 3. Macro (a), optical (b) and SEM (c, d) views of the pumice particles.

is used to determine compressive $1 \%$ proof strength $\left(\sigma_{\mathrm{cmp}}\right)$, in other words $1 \%$ offset yield stress. Following the linear section, stress values decrease depending on sample properties (matrix strength, filler strength, size, type and porosity) and plateau behavior starts. In order to appoint plateau stress $\left(\sigma_{\mathrm{pl}}\right)$ arithmetic mean of the stress values between 0.2 and 0.4 strain is calculated. For finding of energy absorption (W), collected data from the stress-strain curve was integrated up to $50 \%$ strain. Moreover, the energy absorption efficiency $\left(\mathrm{W}_{\mathrm{e}}\right)$ is another parameter and it is described as the ratio of energy absorption value to absorption capacity of perfect foam ${ }^{39}$.

\section{Results and Discussion}

\subsection{Microstructural analysis of pumice particles}

Macro and micro views of the pumice particles can be seen in depth in Figure 3. Owing to its unique structure, pumice has not spherical form contrary to other filler materials used in syntactic foam metals. Pumice particles compose of multiple different sized circular and lengthwise pores as can be seen in Figure $3 \mathrm{c}$ and Figure $3 \mathrm{~d}$. On the other hand, pumice particles may have unwanted contaminants like small stones and sand particles, so the separation step is highly significant to obtain high quality of foam samples. Prior to the main infiltration process, all pumice particles were filtered with proper sieves and their size range was set constant between 2-4 mm.

\subsection{Macro and microstructural analysis of fabricated AMSFS}

Fabricated samples were checked up in terms of both macro and micro properties. Figure 4 illustrates macro views of syntactic foams from different perspectives. Macro observations were carried out for measurement of dimensions and detection of outer surface flaws if they exist. In the light of the macro analysis, it could be said that after sandwich casting there was no imperfections like solidification cracks and evident big pits on matrix surfaces. Since an easy opening sealed split steel mold facilitating sample removal was used in the design of sandwich casting, all syntactic samples had split line marks. Ahead of the compressive loadings, split marks and excess burrs (especially around the top faces of the samples) were grinded and polished sensitively.

The typical microstructure of the manufactured foams is represented in Figure 5. This figure reflects similar features with general MMSFs described in former literature studies ${ }^{9,10}$. Figure 5 demonstrates that all samples have perfect infiltration harmony. Usually, depending on reinforcement type, two kinds of voids, which are in the form of small pores on/ into the body of the filler or are relatively in the form of huge gaps in thin walled spheres, can be present. In our work, we observed perfect infiltration between pumice particles even in quite narrow gaps (Figure 5a) and rough outer surface of the pumice particles (Figure 5d). In some circumstances shown in Figure 5b and Figure 5c, little amount of molten Al may leak into the pumice structure from the outer surface pits or channels, but, compared to engineered hollow sphere ceramics, the effect of this situation is considerably limited due to closed cell structure of pumice.

Only for SF2, a negligible shrinkage cavity shown in Figure 5e with red arrows was detected. It can be asserted about this case that because of different thermal conductivity values of the filler and matrix alloys, that kind of small cavities might form around matrix/filler interface and might occur also rarely in the matrix itself during solidification. In addition, any major breakaway in the inner struts shown with red arrows or deep surface cracks on the pumice particles were not noticed (Figure 5f). This circumstance can be interpreted as a significant advantage from the points of deformation and fracture behavior. 


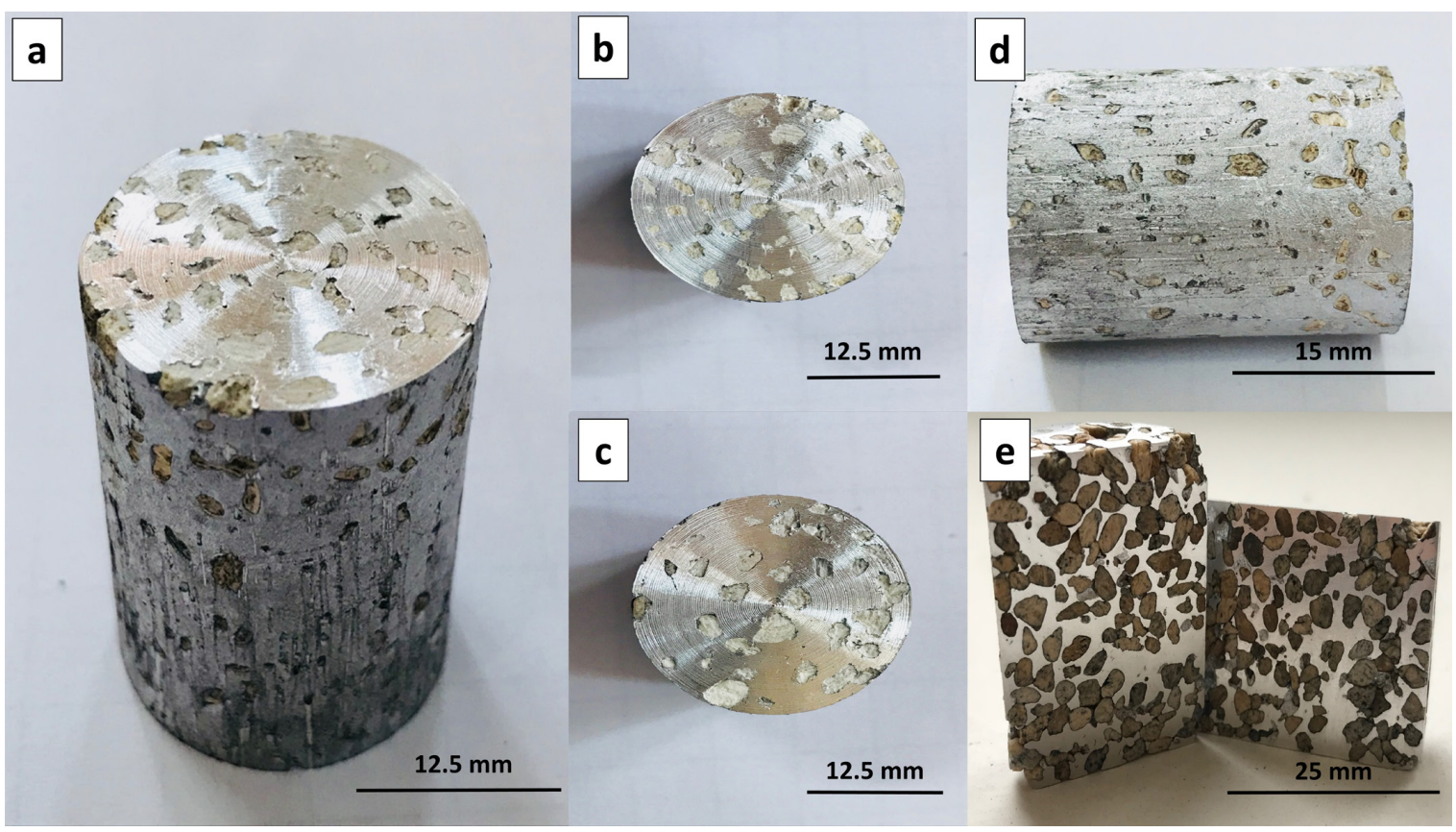

Figure 4. Different views of fabricated Al 7075-pumice foams: 3D (a), top (b), bottom (c), longitudinal (d) and cross sectional (d).

Table 2. Physical properties of fabricated AMSF samples.

\begin{tabular}{cccccc}
\hline Foam No & Diameter $(\mathbf{m m})$ & Height $(\mathbf{m m})$ & $\begin{array}{c}\text { Foam density } \\
\left(\mathbf{g} / \mathbf{c m}^{\mathbf{3}}\right)\end{array}$ & Filler Volume (\%) & Total porosity (\%) \\
\hline SF1 & 24.98 & 33.78 & 1.60 & 59.2 & 40.96 \\
\hline SF2 & 25.14 & 33.80 & 1.42 & 65.4 & 47.50 \\
\hline SF3 & 25.28 & 33.95 & 1.48 & 63.0 & 45.38 \\
\hline SF4 & 24.88 & 32.82 & 1.61 & 59.4 & 40.62 \\
\hline SF5 & 24.97 & 32.58 & 1.42 & 66.2 & 47.39 \\
\hline SF6 & 25.30 & 33.15 & 1.46 & 64.3 & 46.29 \\
\hline
\end{tabular}

\subsection{Physical properties of fabricated AMSFS}

Table 2 given below indicates physical properties of produced samples. Volume fraction of filler particles $\left(\mathrm{F}_{\mathrm{fil}}\right)$, particle density of the fillers $\left(\rho_{\mathrm{fil}}\right)$ and total porosity percentage $\left(\mathrm{F}_{\mathrm{TP}}\right)$ were calculated by using the Equations 1-4;

From Table 2, average density of all produced samples is $1.50 \mathrm{~g} / \mathrm{cm}^{3}$ while the lowest value is $1.42 \mathrm{~g} / \mathrm{cm}^{3}$ (for SF2 and SF5). These values are compatible with A356/pumice foams manufactured by Taherishargh et al.by way of backward infiltration casting ${ }^{36}$. Also, if the measured foam densities are checked up with some other works tried different methods, it can be claimed that relatively low density levels can be obtained by means of sandwich casting method.

Pumice is considerably hard/cellular material and has a lot of small pores on and into its solid body. Thanks to the strong nature of cell walls and very small sized pore structure, it is notably resistant against both crushing under fabrication pressure and matrix leakage into its pores. From the point of fractional behavior of MMSFs, damaged fillers and matrix leakage can be evaluated as undesired circumstances by the reason of the fact that they cause density increasing and can dominate fracture style of the AMSF. In comparison with natural pumice, some engineered hollow fillers used in technical literature such as thin-walled $\mathrm{SiC}$ spheres, special ceramic mixtures and glass micro spheres are more sensitive to cracking and molten matrix penetration ${ }^{1,40}$. Total porosity values of fabricated foams were calculated from Equations 2-4. The result shows that the highest and the lowest porosity levels are $\mathbf{4 7 . 3 9 \%}$ and $\mathbf{4 0 . 6 2} \%$ for SF5 and for SF 4 respectively. According to the further evaluations, through sandwich infiltration technique, all fabricated pumice reinforced syntactics possess averagely $\mathbf{4 4 . 6 9 \%}$ porosity.

Certain researchers like Dunand et al. ${ }^{41}$ emphasized that depending on Si content of reinforcement material, a probable chemical activity written below could be observed. After this chemical reaction, solid crystalline $\mathrm{Al}_{2} \mathrm{O}_{3}$ emerges at matrix/ filler interface, which may affect deformation behavior of the foam by the reason of the fact that $\mathrm{Al}_{2} \mathrm{O}_{3}$ has high stiffness.

$$
\begin{gathered}
4 \mathrm{Al}_{(l)}+3 \mathrm{SiO}_{2(s)} \rightarrow 2 \mathrm{Al}_{2} \mathrm{O}_{3(s)}+3 \mathrm{Si}_{(s)},\left(700-850^{\circ} \mathrm{C}\right) \\
\Delta G=-310 \text { to }-330 \mathrm{~kJ} / \mathrm{mol}
\end{gathered}
$$

Similar to $\mathrm{Al}$ atoms, $\mathrm{Mg}$ atoms may also react with solid $\mathrm{SiO}_{2}$ between $650{ }^{\circ} \mathrm{C}$ and $900^{\circ} \mathrm{C}$ as written below in Equations 6 and $7^{42,43}$.

$$
\begin{gathered}
2 \mathrm{Mg}_{(l)}+\mathrm{SiO}_{2(s)} \rightarrow 2 \mathrm{MgO}_{(s)}+\mathrm{Si}_{(s)},\left(800^{\circ} \mathrm{C}\right) \\
\Delta G=-251.300 \mathrm{~kJ} / \mathrm{mol} \\
\mathrm{SiO}_{2(s)}+4 \mathrm{Mg}_{(l)} \rightarrow \mathrm{Mg}_{2} \mathrm{Si}_{(s)}+2 \mathrm{MgO}_{(s)}\left(800^{\circ} \mathrm{C}\right) \\
\Delta G=-322.865 \mathrm{~kJ} / \mathrm{mol}
\end{gathered}
$$




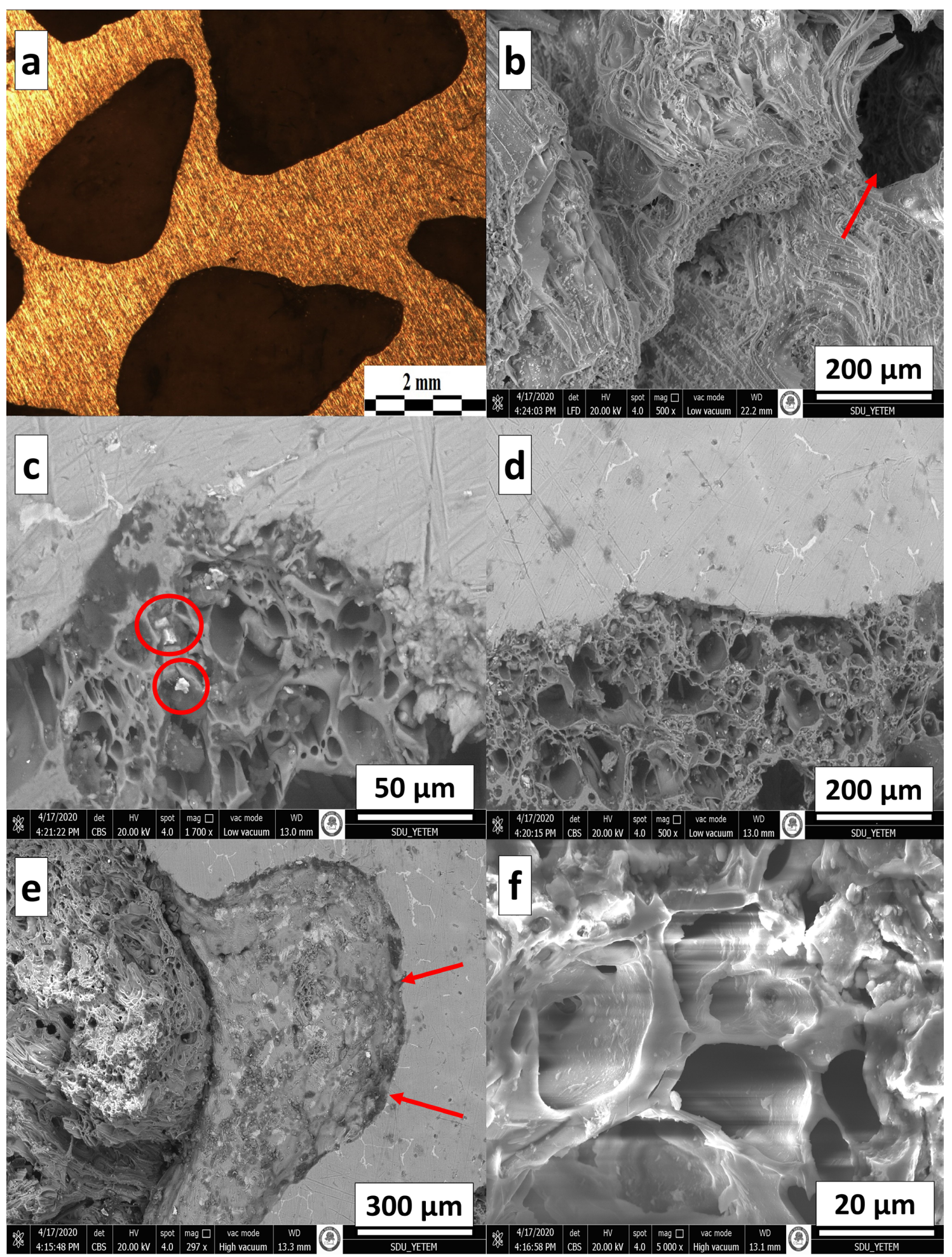

Figure 5. Micro images of fabricated AMSFs; optical view (a) and SEM views (b-f).

Atomic diffusion and chemical activities are considered as controllers for the kinetics of the Equation 5-7. Therefore, main parameters affecting the extent of that kind of reactions are casting duration, infiltration temperature and silicon content of matrix alloy. Since the all infiltration process performed in newly offered sandwich infiltration casting was performed at the low temperature of $720{ }^{\circ} \mathrm{C}$ with the rapid solidification duration of approximately 45 seconds, we did not take the chemical reaction at the Al matrix/ pumice interface into consideration. Moreover, also in the microscopic investigations, any signs of the reaction couldn't be seen. 
(a)

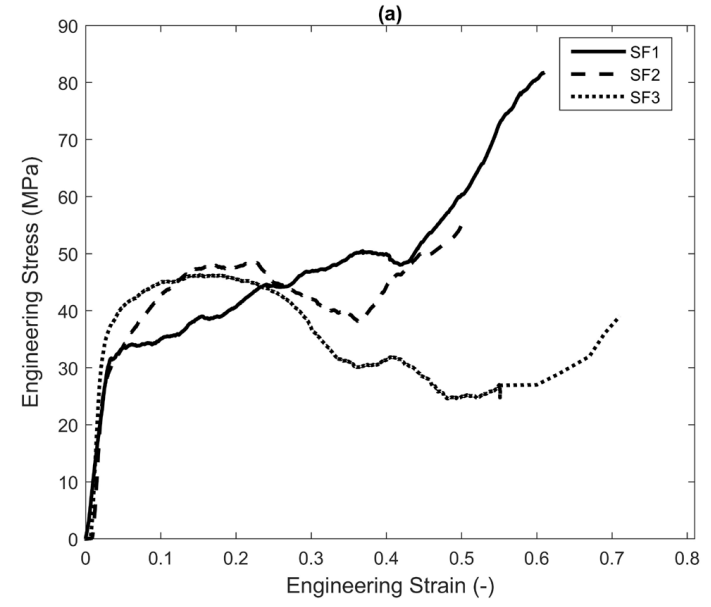

(b)

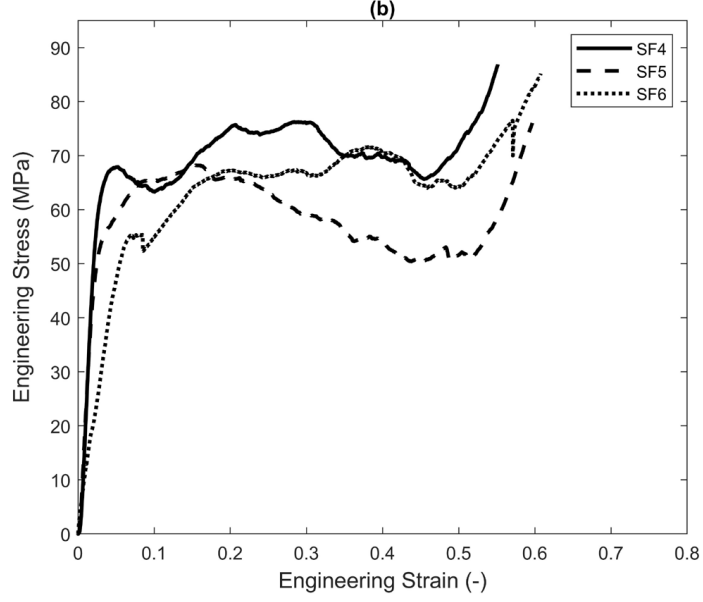

Figure 6. Compressive engineering stress-strain curves of the sandwich filtrated samples: as-cast (a) and heat treated (b).

Table 3. Compressive properties of fabricated AMSFs.

\begin{tabular}{lccccc}
\hline \multicolumn{1}{c}{ Foam No } & $\sigma_{\text {cmp }}(\mathbf{M P a})$ & $\sigma_{\text {pl }}(\mathbf{M P a})$ & $\mathbf{e}_{\text {ple }}$ & $\mathbf{W}\left(\mathbf{M J} / \mathbf{m}^{3}\right)$ & $\mathbf{W}_{\mathbf{e}}(\mathbf{\%})$ \\
\hline SF1 (As-cast) & 31.2 & 46.5 & 0.44 & 21.2 & 0.84 \\
\hline SF2 (As-cast) & 32.5 & 42.9 & 0.41 & 21.1 & 0.87 \\
\hline SF3 (As-cast) & 34.1 & 37.3 & 0.60 & 34.3 & 0.79 \\
\hline SF4 (T6 treated) & 64.6 & 74.3 & 0.46 & 29.0 & 0.89 \\
\hline SF5 (T6 treated) & 53.5 & 59.6 & 0.55 & 30.4 & 0.85 \\
\hline SF6 (T6 treated) & 54.0 & 68.1 & 0.54 & 0.84 \\
\hline
\end{tabular}

\subsection{Compressive properties of fabricated AMSFS}

The compression tests were carried out on all syntactic samples and half of them were subjected to T6 artificial aging heat treatment. The compressive stress-strain curves of as-cast and T6 heat treated AMSFs can be seen in Figure 6a and Figure $6 \mathrm{~b}$ respectively.

Table 3 summarizes the compressive test results. $\sigma_{\text {cmp }}$, $\sigma_{\mathrm{pl}}, \mathrm{e}_{\mathrm{ple}}, \mathrm{W}$ and $\mathrm{W}_{\mathrm{e}}$ are compression strength, plateau stress, plateau end strain value, energy absorption and energy absorption efficiency values respectively.

The compression $1 \%$ proof strength levels of heat treated syntactic foams exceed the corresponding value for as-cast foams at near density values regardless of the filler distribution. As known well from the technical literature ${ }^{37}$, T6 heat treated alloys have higher yield strength levels compared to solid ascast aluminum alloys due to secondary phase precipitations blocking dislocation movements. That circumstance is observed also in AMSF behaviors because Al matrix supports most of the compressive load during deformation. In general, filler materials are insufficient to contribute to the compression strength of the syntactic foams. Maximum and minimum compression $1 \%$ proof strength values are 64.6 and 31.2 MPa for T6 treated SF4 and as-cast SF1 respectively. On the other hand, it can be stated that there is an affirmative effect of density rising on compressive strength of the T6 treated samples since higher density corresponds to higher matrix volume fraction in the syntactic structure.

The plateau stress $\left(\sigma_{\mathrm{pl}}\right)$ is another property of AMSFs and it plays an important role for endurance to deformation during large strain compression and for ability of energy absorption. Similar to $\mathbf{1 \%}$ offset yield strength, the plateau stress values of heat treated samples are utterly higher than these of as-cast foams. Contrary to standard closed cell metal foams or some hollow sphere reinforced syntactic foams, plateau zones of all fabricated foams have irregularities and not smooth by the reason of original structural nature of pumice. Besides, it can be asserted that owing to their complex tubular and circular pores, pumice particles carry a potential for mechanical anisotropy leading to plateau fluctuations. From Figure 6 and Table 3, T6 treated sample of SF4 with the value of 74.3 MPa has higher plateau stress than the others, whereas ascast sample of SF3 has the lowest plateau stress with 37.3 $\mathrm{MPa}$. As a consequence of common evaluation of physical and mechanical properties, it can be reached that there is an affirmative relation between plateau stress and foam density, but sometimes, due to unstable density gradient of the foam and mechanical anisotropy of pumice, there may be opposite cases as observed for SF3.

Area under the stress/strain curve up to $\mathbf{5 0 \%}$ deformation represents capability of energy absorption for the AMSFs. It is clear from the Figure 7 that the heat-treated syntactic foam samples display evidently better performance in terms of energy absorption ability compared to as-cast foams. That improvement can be expressed with high compressive response stress levels of heat treated samples in spite of ductility decrease in matrix. As can be seen from Figure 7c showing energy absorption capabilities between near/same densities, the most serious energy absorption increase (almost $61 \%$ ) is detected between as-cast sample of SF1 and heat treated SF4. The best energy absorption performance belongs to SF4 with $34 \mathrm{MJ} / \mathrm{m}^{3}$ by reason of the fact that it has the highest density of $1.61 \mathrm{~g} / \mathrm{cm}^{3}$ and the lowest porosity of $\mathbf{4 0 . 6 \%}$. 

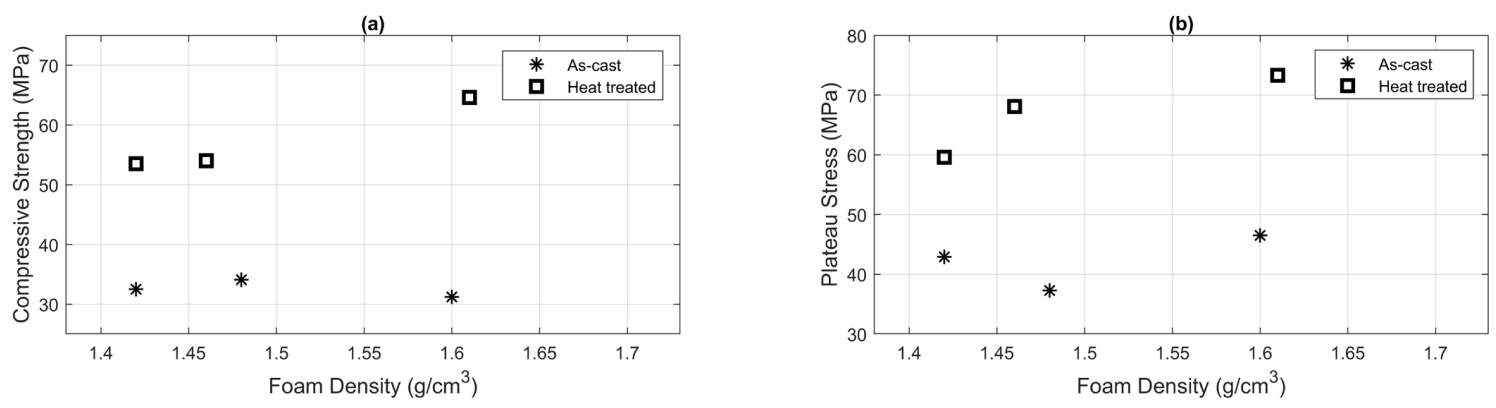

(c)

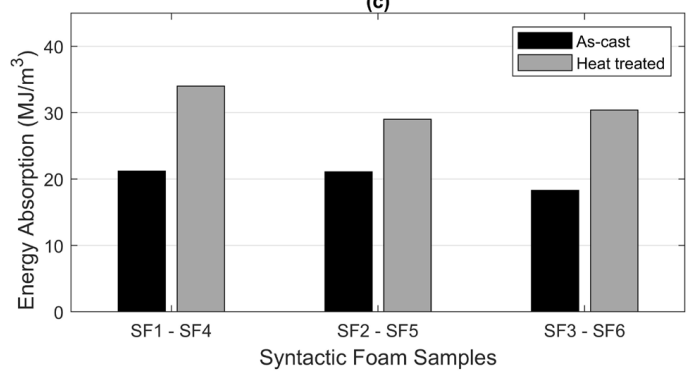

Figure 7. Compressive properties of the Al 7075/pumice syntactic foam: Compressive strength and plateau stress alterations with foam density $(a, b)$ and pairwise comparison of energy absorption according to density similarities (c).

The highest densification strain of 0.60 belongs to SF3 while the lowest value is found as 0.41 for SF2. The difference between densification strain values of pumice filled syntactics is relatively high in comparison with engineered hollow sphere filled foams because of better roundness and homogenous inner structures of thin walled spheres. However, with the average of 0.5 densification strain pumice material can be considered as a promising alternative to expensive engineered ceramic spheres. There is a general approach that the main mechanical features of metal syntactic foam $\left(\sigma_{\mathrm{cmp}}, \sigma_{\mathrm{pl}}, \mathrm{e}_{\mathrm{ple}}\right.$ and $\left.\mathrm{W}\right)$ improve with its density, but sometimes, some minor differences may be observed between almost same or close density foams. In this point, it can be interpreted that heterogeneous distribution of fillers (random filling/packing), non-uniform size and shape of the filler particles and influence of mechanical anisotropy due to irregular porous structure of filler materials are main reasons.

According to the results stated in Table 1 and Table 2, the energy absorption efficiency is not related to the foam density as observed for other kinds of $\mathrm{MMSFs}^{33}$ and it can be interpreted as an independent parameter. From Table 2, the energy efficiency values of samples vary between 0.79 and 0.89 (SF3 and SF4). The term of efficiency depends highly on ideal plateau behavior during deformation, so it can be emphasized that the flatter the plateau region is, the higher energy absorption efficiency can be reached ${ }^{39}$. Since all pumice particles are unique in terms of pore structure and the average size distribution is not constant for different samples, both as-cast and heat treated samples have oscillations in their plateau regions. In addition to this, it is correct to express that there is no relationship between the energy absorption efficiency and heat treatment for all samples. While the heat treated sample of SF4 has the highest efficiency with 0.89 , the average of all types of foams is 0.85 .

\subsection{Failure mechanism}

When the deformation mechanisms of the AMSFs are analyzed together with the observations conducted in former investigations ${ }^{1,13,24,44}$, it is seen that there are several different failure characteristics as depicted schematically in Figure 8 . Strength of matrix alloy, crush strength and pore structure of filler materials, fabrication technique and heat treatment state of aluminum alloy are the most significant factors affecting main failure mechanism of the AMSFs. If insufficient lubrication is applied on the compression contact surfaces before the loading and the matrix has enough ductility, failure style emerges in the form of barreling (Figure 8a). If the density gradient is present in the fabricated foam body, specific deformation zones is detected (Figure 8b, Figure 8c and Figure 8d). Nevertheless, when the matrix flow strength surpasses the crush strength of the fillers or any heat treatment process is applied to the alloy, failure style of the fabricated AMSF displays brittle characteristics due to various crack types (Figure 8e, Figure 8f and Figure 8h).

The compressive properties of the MMSFs are considerably related to the deformation style of whole foam body. In this context, there is an apparent dissimilarity between mechanical behavior of pumice reinforced as-cast samples and $\mathrm{T} 6$ treated foam samples. This circumstance stems from increased matrix brittleness following $\mathrm{T} 6$ treatment and mechanical anisotropy of pumice particles having different directional pores. Figure 9 and Figure 10 illustrates different failure mechanisms of ascast $\left(1.61 \mathrm{~g} / \mathrm{cm}^{3}\right)$ and heat treated $\left(1.60 \mathrm{~g} / \mathbf{c m}^{3}\right)$ foams in detail during and after the compression test respectively.

At the beginning of the deformation, there is a sharp increment in the stress values following elastic deformation of the metal matrix and pumice particles together. As can be seen from Figure 9a and Figure 10a, at 10\% deformation, both as-cast and heat treated samples start to bulge and deform 

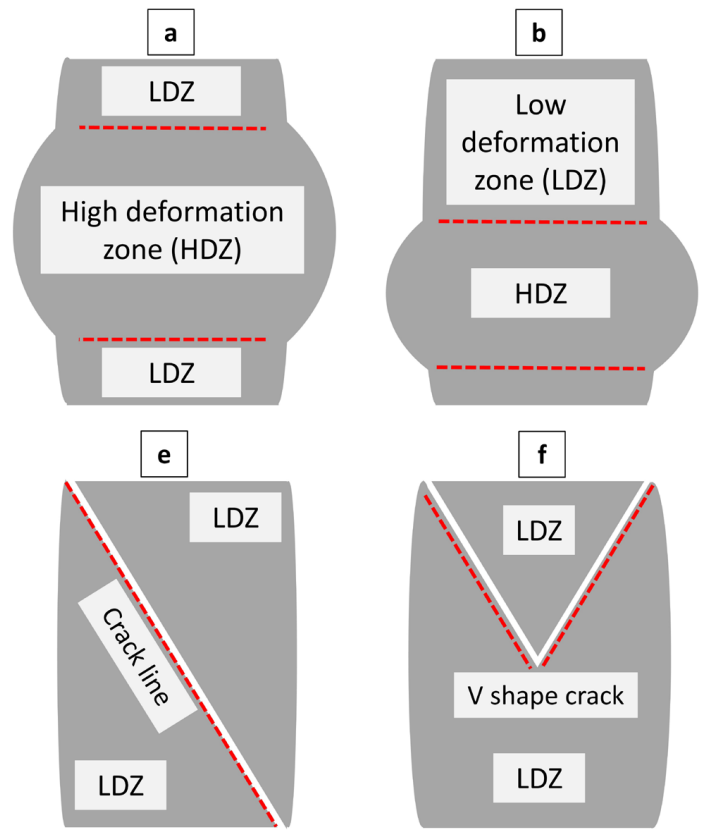
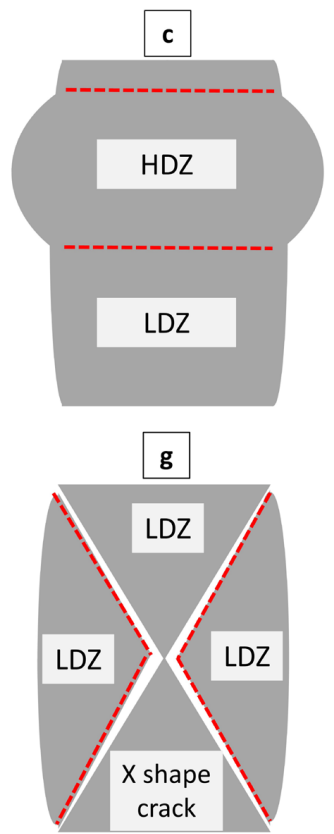
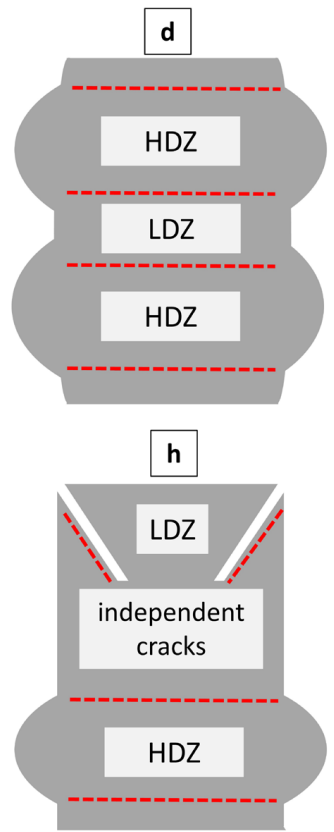

Figure 8. Schematic view of the probable failure styles of the AMSFs; middle barreling(a), bottom barreling(b), top barreling(c), double barreling(d), $45^{\circ}$ brittle fracture(e), $v$ shape $\operatorname{crack}(\mathrm{f}), \mathrm{x}$ type $\operatorname{crack}(\mathrm{g})$ and mixed type deformation(h),

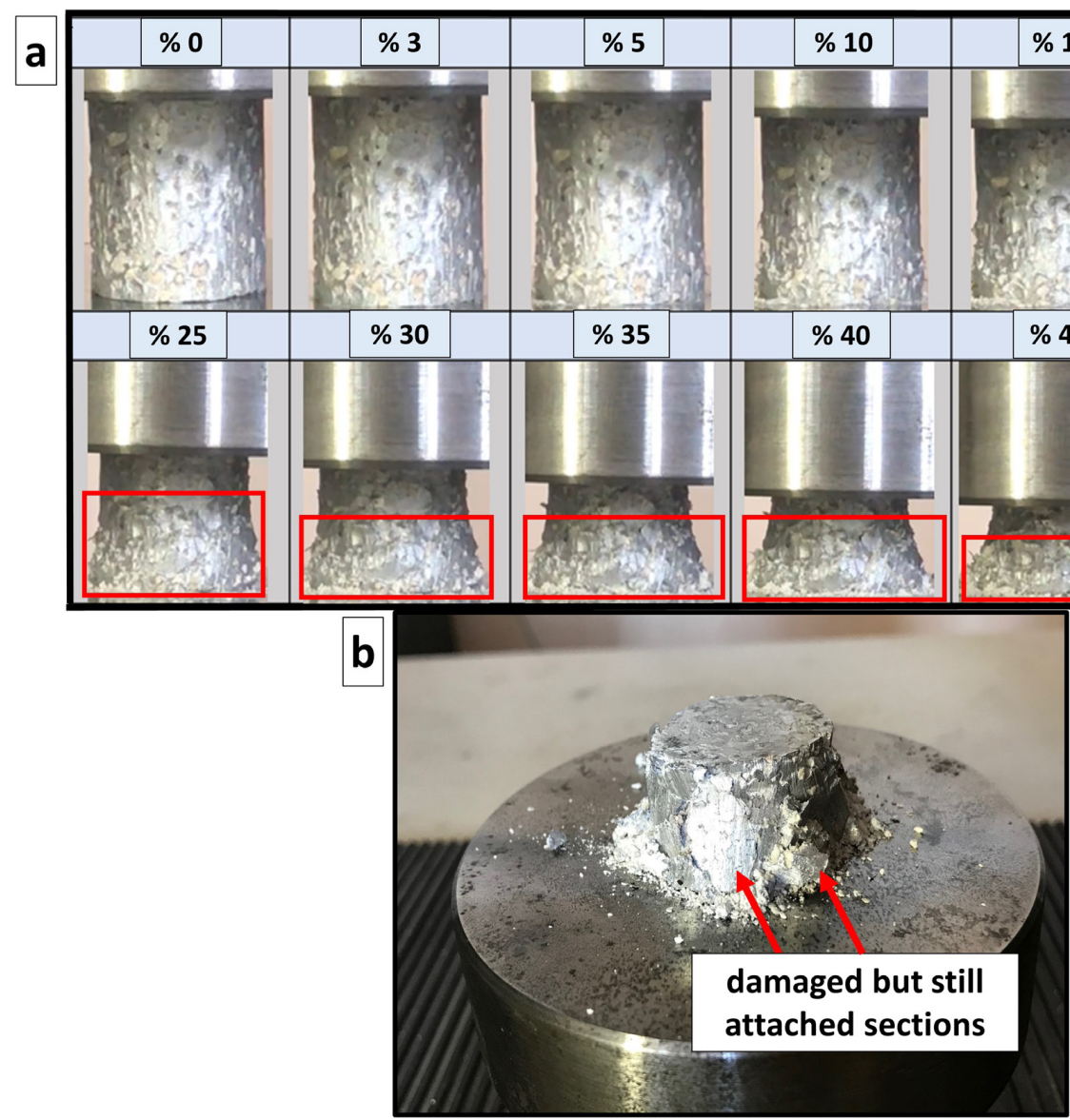

Figure 9. Deformation mechanism of the as-cast syntactic foam sample; during (a) and after (b). 
plastically due to activated dislocation mechanism. Following the localized bulging, stress values go up at a lower rate up to $\mathbf{2 0 \%}$ strain in the as-cast sample. Moreover, although the sample has a tendency for bulging from its bottom side, other sections of the foam remain majorly un-deformed or little deformed, and that sections can be named as dead zones (Figure 9a). This behavior can be attributed to existence of density gradient in the foam body ${ }^{45}$. Volume of the local porosity in the bulged zones is higher than the other zones, so it is true to say that some sections having higher porosity deform earlier due to deformation localization. Besides, the as-cast sample displays relatively uniform deformation accompanied with some minor cracks owing to its superior ductility up to $\mathbf{4 0 \%}$ strain. Upon further compression, bottom side bulging effect maximizes and multiple small cracks and shear bands become more evident between at $\mathbf{4 0 \%}$ and $\mathbf{5 0 \%}$ deformation. When the plateau region approaches to the end, all shear bands pile up that culminate in even deformation. At the end of the plateau region, the densification stage begins and measured stress values begin to climb quickly as predicted one since majority of the pumice particles damage and there is no more porosity in the foam body. According to these findings, the main failure mechanism of the as-cast sample can be defined as ductile deformation dominated mixed type failure. Also, perfect infiltration can be created even in very narrow gaps by means of the sandwich infiltration casting technique. The method uses free fillers contrary to other methods utilizing preforms, this circumstance is effective to prevent early crack propagation for the as-cast sample since propagated crack faces ductile matrix after brittle pumice particles. Based on metal matrix flow strength and filler crush strength, fracture style of the AMSFs turns from ductile deformation (barreling or bulging styles) to brittle fracture (v, x or mixed shaped cracks) ${ }^{44}$. Pumice is an igneous cellular rock having different shape and oriented pores. Owing to its higher compression strength, pumice with parallel oriented structural pores to the loading direction shows better failure performance. For some as-cast samples (SF2 and SF3), immediately after the peak stress point, stress values decrease because certain pumice particles experience less deformation depending upon their pore orientation in terms of compression axis. Compared to pumice or other types of natural base porous fillers, it can be stated this kind of stress drop is seen more clearly in engineered hollow sphere filled MMSFs ${ }^{35,46}$ because of the simultaneous failure and identical structural properties of the spheres.

As for the heat treated sample, its behavior at early stages of the compression is very similar with the as-cast sample due to elastic deformation, but from this point on, typical failure characteristics of these two samples differ in a noteworthy manner. Figure 10a indicates that the T6 treated sample exhibits both ductile (bottom side bulging) and brittle (independent multiple cracks at $45^{\circ}$ and at other acute angles)
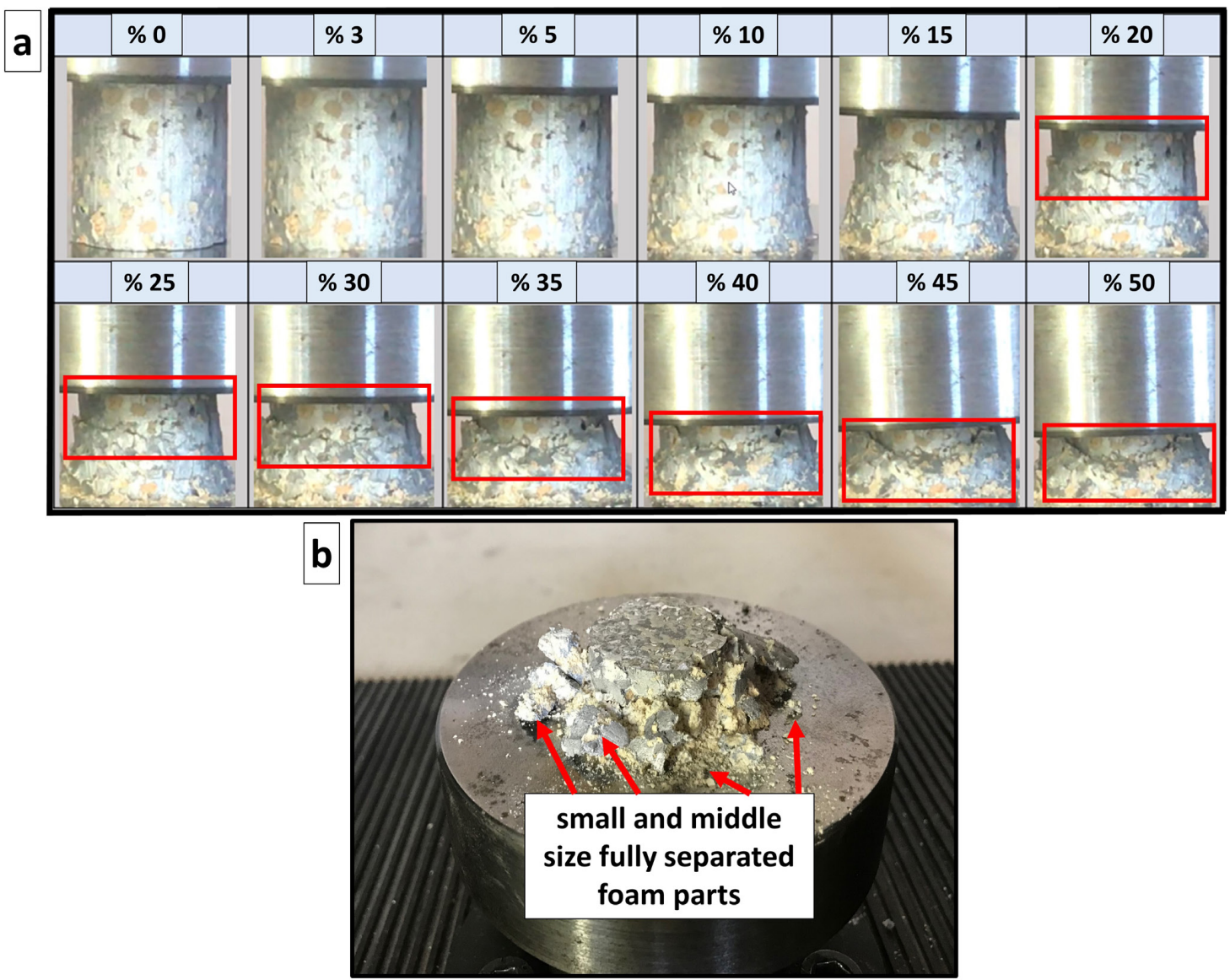

Figure 10. Deformation mechanism of the heat treated syntactic foam sample; during (a) and after (b). 
deformation. At $\mathbf{2 5 \%}$ and subsequent deformation, brittle deformation with $\mathrm{v}$ type major crack dominates the ductile bulging effect in terms of damage characteristic. Because of the aging treatment, although the yield strength of the matrix metal improves, fracture toughness and ductility diminish, so probability of rapid crack propagation between pumice particles also increases. As long as the plastic deformation continues, $\mathrm{v}$ shaped crack gets deep and accelerates fragmentation of the foam body. Additionally, different deformation zones and dead zones are observed in a fashion similar to the as-cast sample as a result of local bulging and v shaped crack. After the compressive loading, from Figure 10b, it is observed that lots of fragments having different volumes break off from the main foam body. If this behavior of the T6 treated sample is checked up on with the as-cast version, it can be expressed that even though both of them show mixed type of deformation, dominant deformation types are quite opposite. Contrary to the T6 treated sample, thanks to its ductile matrix structure, inner or surface cracks in the as-cast sample can't propagate easily between the pumice particles. Figure $10 \mathrm{~b}$ depicts that when the compressive loading is removed, the heat treated sample divides into many unlike pieces and lose its monolithic body structure. Nevertheless, the as-cast sample remains majorly one-piece except for some small fragments

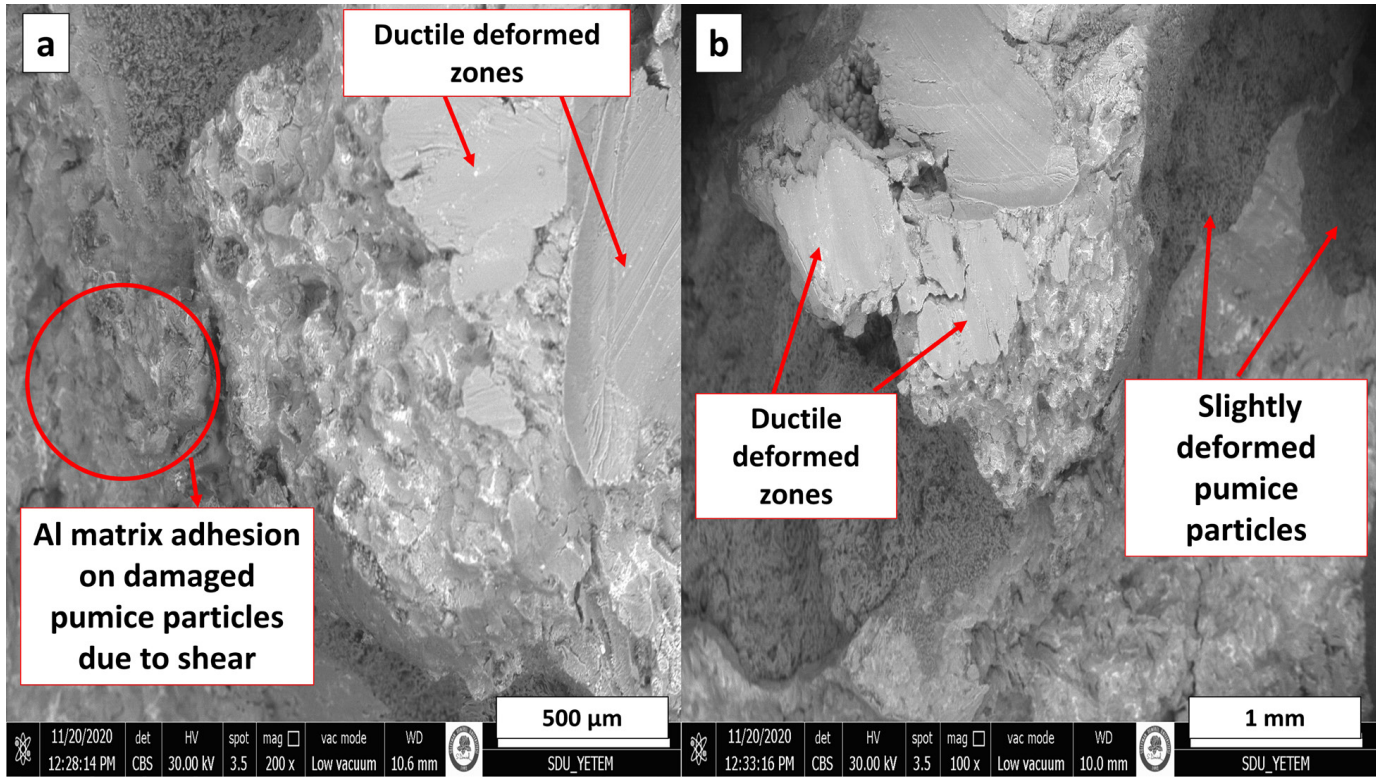

Figure 11. SEM images of deformed zones of the as-cast sample; ductile matrix adhesion on the filler materials(a) and ductile deformation with some slightly deformed fillers(b).

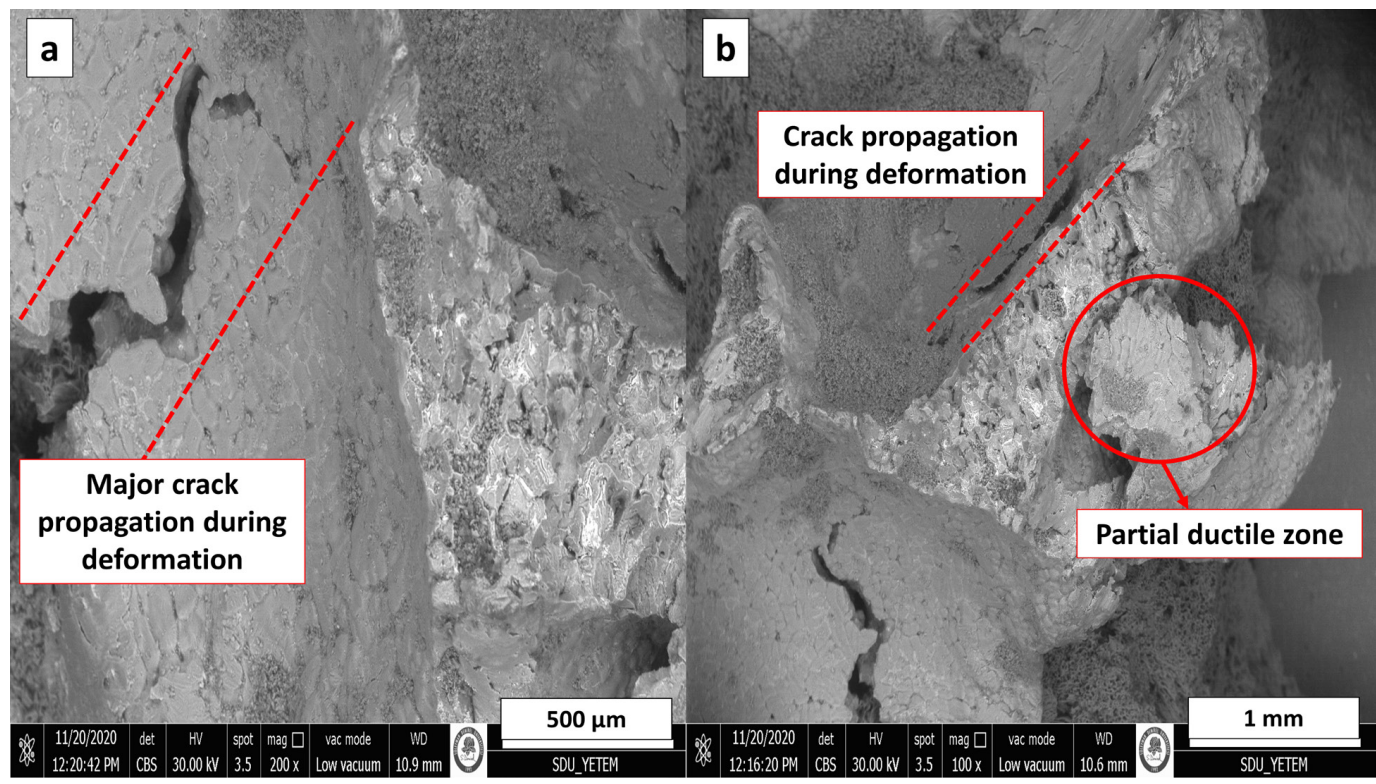

Figure 12. SEM images of deformed zones of the heat treated sample; major crack propagation(a) and brittle fracture dominated mixed deformation(b).v 
(Figure 9b). Similarly, according to after deformation micro images given in Figure 11 and Figure 12, major difference between these two samples can be seen easily and it is obvious that the T6 treatment influences notably fracture/damage behavior of the foam. From Figure 11a and Figure 11b, ductile shear zones are present on the matrix for the as-cast sample. However, apparent major crack propagations (marked with dashed lines in Figure 12a and Figure 12b) on the Al matrix can be seen as a result of the effect of heat treatment on the brittleness of the matrix. In this point, it can be asserted that T6 treatment enhances the principle compressive properties, but at the same time, it leads to mixed type deformation in which brittle characteristic is dominant phase.

\section{Conclusions}

1) New offered sandwich infiltration casting is an effective method for production of Al 7075/pumice syntactic foam and can also be used for other kinds of filler materials. This method doesn't require any additional high-cost apparatus and sophisticated designs compared to the other alternatives. By optimizing the process parameters, molten $\mathrm{Al}$ matrix can be filtered between very narrow gaps.

2) Micro investigations show that with the pressure of $0.1 \mathrm{MPa}$ almost perfect infiltration can be obtained at the melting temperature of $720^{\circ} \mathrm{C}$. Density values of all fabricated samples range between 1.42 and $1.61 \mathrm{~g} / \mathrm{cm}^{3}$. As long as the foam density goes up, compression strength and plateau strength gain upward tendency in the heat treated samples. Due to the fact that heat treatment increases matrix strength, T6 treated samples have higher compression strength than the as-cast ones.

3) For all samples, total porosity values are determined by physical structure of tubular and circular pores on and into the pumice particles and vary between $\mathbf{4 0 . 6 2 \%}$ and $\mathbf{4 7 . 3 9 \%}$.

4) Plateau stress is an important parameter for syntactic foams because of its decisiveness on energy absorption. The highest plateau stress belongs to T6 treated sample of SF4 with 74.3 MPa.

5) Energy absorption ability is directly affected by heat treatment in a positive manner and all T6 aged samples have bigger area under their stress-strain graphs. Compared to other expensive ceramic spheres, pumice contributes perfectly to energy absorption ability of the fabricated AMSFs by the reason of its unique extremely porous structure. It can be also expressed that there is no major difference on energy absorption efficiency. The peak value of $\mathbf{8 9 \%}$ efficiency is reached by T6 treated foam of SF4.

6) In spite of their ruptured and damaged sections, ascast versions of AMSFs remain largely one-piece owing to relatively high ductility of the Al matrix and usage of the free pumice particles. By means of sandwich casting design, compared to alternative techniques using preform shape fillers, rapid crack propagation can be hindered by ductile $\mathrm{Al}$ matrix due to perfect infiltration even succeeded in quite narrow gaps.
7) Heat treatment changes the deformation style of the syntactics by allowing multiple body separations and influences considerably matrix deformation behavior by decreasing ductility of the alloy. Compared to as-cast foams, heat treated foams exhibit more brittle behavior even though their quasi-static compressive features are superior.

\section{Acknowledgement}

We thank to the assistance of team in micro characterization unit at Innovative Technologies and Application Research Center (YETEM), Suleyman Demirel University, Isparta, Turkey.

\section{References}

1. Zhang LP, Zhao YY. Mechanical response of Al matrix syntactic foams produced by pressure infiltration casting. J Compos Mater. 2007;41(17):2105-17.

2. Rohatgi PK, Kim JK, Gupta N, Alaraj S, Daoud A. Compressive characteristics of A356/fly ash cenosphere composites synthesized by pressure infiltration technique. Compos, Part A Appl Sci Manuf. 2006;37:430-7.

3. Rohatgi PK, Gupta N, Schultz BF, Luong DD. The synthesis, compressive properties, and applications of metal matrix syntactic foams. J Miner Met Mater Soc. 2011;63:36-42.

4. Orbulov IN. Compressive properties of aluminum matrix syntactic foams. Mater Sci Eng A. 2012;555:52-6.

5. Mondal DP. Titanium-cenosphere syntactic foam made through powder metallurgy route. Mater Des. 2012;34:82-9.

6. Rabiei A, Neville B, Reese N, Vendra L. New composite metal foams under compressive cyclic loadings. Mater Sci Forum. 2007;539-543:1868-73.

7. Pan L, Yang Y, Ahsan MU, Luong DD, Gupta N, Kumar A, et al. Zn-Matrix syntactic foams: effect of heat treatment on microstructure and compressive properties. Mater Sci Eng A. 2018;731:413-22.

8. Zhang Q, Lee PD, Singh R, Wu G, Lindley TC. Micro-CT characterization of structural features and deformation behavior of fly ash/aluminum syntactic foam. Acta Mater. 2009;57:300311.

9. Licitra L, Luong DD, Strbik OM 3rd, Gupta N. Dynamic properties of alumina hollow particle filled aluminum alloy A356 matrix syntactic foams. Mater Des. 2015;66:504-15.

10. Gupta N, Luong DD, Cho K. Magnesium matrix composite foams: Density, mechanical properties, and applications. Metals (Basel). 2012;2:238-52.

11. Taherishargh M, Belova IV, Murch GE, Fiedler T. Low-density expanded perlite-aluminum syntactic foam. Mater Sci Eng A. 2014;604:127-34.

12. Vishwakarma A, Mondal DP, Birla S, Das S, Prasanth N. Effect of cenosphere size on the dry sliding wear behavior LM13cenosphere syntactic foam. Tribol Int. 2017;110:8-22.

13. Orbulov IN, Szlancsik A. On the mechanical properties of aluminum matrix syntactic foams. Adv. Eng. Mater. 2018;20(5):131-41.

14. Banhart J. Aluminum foams: on the road to real applications. MRS Bull. 2003;28(4):290-5.

15. Orbulov IN, Dobránszky J. Producing metal matrix syntactic foams by pressure infiltration. Periodica Polytechnica. 2008;52(1):35-42.

16. Mondal DP, Das S, Jha N. Dry sliding wear behavior of aluminum syntactic foam. Mater Des. 2009;30(7):2563-8.

17. Castro G, Nutt SR. Synthesis of syntactic steel foam using gravity-fed infiltration. Mater Sci Eng A. 2012;553:89-95.

18. Castro G, Nutt SR. Synthesis of syntactic steel foam using mechanical pressure infiltration. Mater Sci Eng A. 2012;535:274-80. 
19. Lin $Y$, Zhang Q, Ma X, Wu G. Mechanical behavior of pure $\mathrm{Al}$ and $\mathrm{Al}-\mathrm{Mg}$ syntactic foam composites containing glass cenospheres. Compos, Part A Appl Sci Manuf. 2016;87:194202.

20. Akinwekomi AD, Adebisi JA, Adediran AA. Compressive characteristics of aluminum-fly Ash syntactic foams processed by microwave sintering. Metall Mater Trans, A Phys Metall Mater Sci. 2019;50:4257-60.

21. Szlancsik A, Katona B, Károly D, Orbulov IN. Notch (In) sensitivity of aluminum matrix syntactic foams. Materials (Basel). 2019;12(4):574.

22. Taherishargh M, Linul E, Broxtermann S, Fiedler T. The mechanical properties of expanded perlite-aluminium syntactic foam at elevated temperatures. J Alloys Compd. 2018;737:5906.

23. Goel MD, Parameswaran V, Mondal DP. High strain rate response of cenosphere-filled aluminum alloy syntactic foam. J Mater Eng Perform. 2019;28:4731-9.

24. Su M, Wang H, Hao H. Compressive properties of aluminum matrix syntactic foams prepared by stir casting method. Adv Eng Mater. 2019;21(8):1900183.

25. Fiedler T, Al-Sahlani K, Linul PA, Linul E. Mechanical properties of A356 and ZA27 metallic syntactic foams at cryogenic temperature. J Alloys Compd. 2020;813:152181.

26. Orbulov IN, Szlancsik A, Kemény A, Kincses D. Compressive mechanical properties of low-cost, aluminium matrix syntactic foams. Compos, Part A Appl Sci Manuf. 2020;135:105923.

27. Fiedler T, Movahedi N, York L, Broxtermann S. Functionally-graded metallic syntactic foams produced via particle pre-compaction. Metals (Basel). 2020;10:314.

28. Su M, Wang H, Hao H, Fiedler T. Compressive properties of expanded glass and alumina hollow spheres hybrid reinforced aluminum matrix syntactic foams. J Alloys Compd. 2020;821:153233.

29. Thalmaier G, Sechel NA, Vida-Simiti I. Syntactic aluminum foam from recycled sawing chips. J Miner Met Mater Soc. 2020;72:3377-82.

30. Sahu S, Ansari MZ, Mondal DP. Microstructure and compressive deformation behavior of 2014 aluminium cenosphere syntactic foam made through stircasting technique. Mater Today-Proc. 2020;25:785-8.

31. Broxtermann S, Su M, Hao H, Fiedler T. Comparative study of stir casting and infiltration casting of expanded glass-aluminium syntactic foams. J Alloys Compd. 2020;845:155415.

32. Taherishargh M, Belova IV, Murch GE, Fiedler T. On the mechanical properties of heat-treated expanded perlite-aluminium syntactic foam. Mater Des. 2014;63:375-83.
33. Movahedi N, Murch GE, Belova IV, Fiedler T. Effect of heat treatment on the compressive behavior of zinc alloy ZA27 syntactic foam. Materials (Basel). 2019;12:792.

34. Dorian K, Balch J, O'Dwyer G, Davis R, Cady CM, Gray GT, et al. Plasticity and damage in aluminum syntactic foams deformed under dynamic and quasi-static conditions. Mater Sci Eng A. 2005;391:408-17.

35. Santa Maria JA, Schultz BF, Ferguson JB, Al-Al Rohatgi PK. ${ }_{2} \mathrm{O}_{3}$ syntactic foams - Part I: effect of matrix strength and hollow spheresize on the quasi-static properties of Al-A206/ $\mathrm{Al}_{2} \mathrm{O}_{3}$ syntactic foams. Mater Sci Eng A. 2013;582:415-22.

36. Taherishargh M, Belova IV, Murch GE, Fiedler T. Pumice/ aluminum syntactic foam. Mater Sci Eng A. 2015;635(21):102-8.

37 ASM International. ASM Handbook. Vol. 4: Heat Treating. Novelty, OH: ASM Handbook Committee; 1991 p. 841-879.

38. Koch GH, Kolijn DT. The heat treatment of the commercial aluminum alloy 7075. J. Heat Treating. 1979;1:3-14.

39. ISO: International Organization for Standardization. ISO 13314-2011: Mechanical Testing of Metals - Ductility TestingCompression Test for Porous and Cellular Metals. Geneva: ISO.

40. Peroni L, Scapin M, Avalle M, Weise J, Lehmhus D. Dynamic mechanical behavior of syntactic iron foams with glass microspheres. Mater Sci Eng A. 2012;552:364-75.

41. Balch DK, Dunand DC. Load partitioning in aluminum syntactic foams containing ceramic microspheres. Acta Mater. 2006;54(6):1501-11.

42. Iwadate Y, Ohgane K, Ohkubo T. Magnesiothermic reduction of silicon dioxide to obtain fine silicon powder in molten salt media: analysis of reduction mechanism. Electrochemistry. 2018;86(4):198-201.

43. Deshmukh PY, Peshwe DR, Bhatt J, Pathak SU. Synthesis and characterization of $\mathrm{Al}-\mathrm{Mg}-\mathrm{SiO}_{2}$ particulate composite using amorphous $\mathrm{SiO}_{2}$ from rice husk ash. Trans Indian Inst Met. 2011;64(6):575-81.

44. Katona B, Szlancsik A, Tábi T, Orbulov IN. Compressive characteristics and low frequency damping of aluminum matrix syntactic foams. Mater Sci Eng A. 2019;739:140-8.

45. Al-Sahlani K, Broxtermann S, Lell D, Fiedler T. Effects of particle size on the microstructure and mechanical properties of expanded glass-metal syntactic foams. Mater Sci Eng A. 2018;728:80-7.

46. Luong DD, Strbik OM 3rd, Hammond VH, Gupta N, Cho $\mathrm{K}$. Development of high performance lightweight aluminum alloy/SiC hollow sphere syntactic foams and compressive characterization at quasi-static and high strain rates. J Alloys Compd. 2013;550:412-22. 